\title{
Effects of a 24 Week Multifaceted Sports Training Program on Some Physical Characteristics of 5 to 9 Year-Old Children
}

\author{
Emre Bağc1 \\ Correspondence: Emre Bağc1, Gazi University, Faculty of Sports Sciences, Ankara, Turkey. \\ Received: July 26, $2017 \quad$ Accepted: September 13, $2017 \quad$ Online Published: September 14, 2017 \\ doi:10.11114/jets.v5i10.2552 URL: https://doi.org/10.11114/jets.v5i10.2552
}

\begin{abstract}
This study was conducted to investigate the effects of a 24 -week multifaceted sport training program on some physical and performance characteristics of 5-9 year old children. There are many researches about the necessities for children to start physical activity at an early age. According to the characteristics of different physical activities to be performed, children can endow with different developments. Multifaceted development in the motor properties of an unbranched individual will also benefit him/her in the branching phase. A branch that will be applied to children will develop the characteristics of that branch in the child. This study aims to determine the effects of the implementation of a training program consisting of the basic characteristics of different branches on the physical characteristics of children.

A group of children with a mean age of $6.4(\mathrm{SD} 1.34)(\mathrm{n}=98)$ residing in Ankara participated in the study. A training program including basic techniques of many sports branches was applied to children in the form of 2 lesson hours per day for 2 days in each week. Lessons are scheduled for 45 minutes. During the 24-week training period, children were tested and measured three times; at the beginning, in the middle and at the end of the study. All physical characteristics of the children within the scope of the study has improved, and the differences in the test of vertical jump, throwing medicine ball, right foot balance posture, left hand grip force, shuttle, horizontal jump and 10x5m running were found to be statistically significant $(\mathrm{p}<0.05)$.
\end{abstract}

Keywords: training, physical fitness, children, sport

\section{Introduction}

Abundant number of studies has been carried out about the health problems and their effects caused by immobility. According to the World Health Organization data, three million deaths and 32 million disability status occur each year due to low physical activity (http://www.who.int/gho/ncd/risk_factors/physical_activity_text/en/). The habit of sedentary life begins at a young age, and it is not so easy for adults to pick up a physically active life style after a childhood period lived away from exercises (Engelen et al., 2013). In addition to making children get into the habit of doing sports at a young age, regular exercise is also necessary for their healthy growth. There is no reason to believe that physical activity is less necessary for pre-school children (Cadenas-Sanchez et al., 2016) (Padilla-Moledo, Ruiz, Ortega, Mora, \& Castro-Pinero, 2012).

It is reported that the lowness of cardiovascular fitness and muscle strength levels in children is associated with the weakness in bone mass, metabolic risk factors, cardiovascular diseases and premature death rates (Cadenas-Sanchez et al., 2016; Ortega, Silventoinen, Tynelius, \& Rasmussen, 2012; Ruiz Et al., 2009; Smith et al., 2014; Strong et al., 2005; Sağıroğlu et al., 2016). In addition, studies have shown that the increase of moderate-intensity exercise plans at least 1 hour per day for the children aged 9-15 years is especially important in terms of cardiovascular health (Andersen et al., 2006). In a research review for associating the increase in muscular fitness levels of individuals with their health, it was emphasized that the increase in muscle fitness level also positively affects general health (Smith et al., 2014).

Physical fitness assessments of children and adolescents are also important for public health. Involvement in regular physical activity during childhood provides many positive developments on the characteristics such as physical fitness, skeletal system (Andersen et al., 2006) and psychosocial (Lobo \& Winsler, 2006) adequacy (Engelen et al., 2013). Similarly, physical inactivity is associated with an increased risk of chronic non-communicable diseases generally continuing in adulthood. Also, there is a relationship between BMI values in childhood and type 2 diabetes, hypertension and coronary diseases that will be experienced during adulthood (Park, Falconer, Viner, \& Kinra, 2012; Weiss \& Raz, 2006). 
Despite some uncertainty of whether there is a relationship between physical fitness and academic success, a study has shown a positive relationship between muscle strength and academic achievement (Chomitz et al., 2009; Padilla-Moledo et al., 2012). Studies have reported that short-term physical activities or exercises to be applied by children also help children develop not only physical performance but also cognitive performance (Chang, Labban, Gapin, \& Etnier, 2012; Jager, Schmidt, Conzelmann, \& Roebers, 2014). It has been stated that school-aged children need to participate in 60 minute fun activities that are appropriate for their levels (Strong et al., 2005).

Another risk factor for children is obesity risk arising due to immobility. Unhealthy, unbalanced diet and lack of activity in childhood seriously increase the risk of obesity in children. Applying a diet to children so that making them lose weight in this way is not very useful method. For this reason, more physical activity should be emphasized (Tan, Chen, Sui, Xue, \& Wang, 2017). However, no matter how much physical activity is used as a measure against obesity, the exercises to be applied for children should not be considered only as a way of prevention from obesity (Weiss \& Raz, 2006). The main reason for being overweight can be explained by energy imbalance. Overweightness can occur in children who cannot spend in-taken energy with exercises (Martin-Garcia et al., 2016).

It has always been a question for parents which sports branch their children need to start at the age of 2-3. They must direct the child towards the activities that he/she can perform with his own body weight, primarily in the form of a game. Generally, children who start to join sport activities with a game form should be aimed at branching when they reach 8-9 years old. In this context, the aim of this research is to prioritize the physical achievements of 5-9 year-old children when they include a program that consists of basic movement education of many branches instead of a single branch.

\section{Material and Method}

A total of 98 children (52 girls, 46 boys) with an average age of 6.48 residing in the province of Ankara participated in this research.

Table 1. Basic characteristics of children participating in the study

\begin{tabular}{lccccc}
\hline Parameters & $\mathrm{N}$ & Lowest & Highest & Average & Std. Dev. \\
\hline Body weight $(\mathrm{kg})$ & 98 & 14 & 45 & 23.10 & 5.92 \\
\hline Length $(\mathrm{cm})$ & 98 & 99 & 151 & 117.5 & 10.14 \\
\hline BMI $\left(\mathrm{kg} / \mathrm{m}^{2}\right)$ & 98 & 10 & 26 & 16.55 & 2.52 \\
\hline
\end{tabular}

\subsection{Multifaceted Sports Training}

Purpose of the multifaceted training program is to ensure that children receive training without depending on a single sports branch. For this reason, the children are provided a multiple program consisting of sports disciplines in different classifications. In the program, individual sports, team sports, racket/paddle sports, competitive sports under the titles of sports branches have been identified. The children were conducted a total of 4 hours/week of physical activity in the form of two lesson hours (45 minutes for one lesson) per day in two days per week. Gymnastics and swimming as the two hours of the weekly four hour schedule were practiced every week without any change in the schedule. In the other 2 lesson hours, two different branch trainings were given and these branches were changed every 4 weeks period. As the branches were targeted, sports branches in various classifications were taken into the program because of the multifaceted development aimed at children. Basic sports (gymnastics, swimming, and athletics), team sports (basketball, football, volleyball, and handball), racquet sports (badminton, tennis, and table tennis), competitive sports (wrestling, karate) and other sports branch (dance, shooting) are applied to the participant children. Materials suitable for the children's age were used in the training programs. The children were tested and measured at the beginning, in the middle, and at the end of the program, in terms of height, body weight, BMI, vertical jump, medicine ball throwing, balance posture, grip force, twisted arm bar hanging, shuttle run, sit-and-reach flexibility test, horizontal jump, 10x5m running. The measurements were performed under the same conditions and with the same protocols.

\subsection{Data Analysis}

The data were collected for this article mainly from survey forms and database registrations. Analysis of the data was conducted using SPSS for Windows v20. One-way ANOVA was used for comparison of the mean for the related groups, and TUKEY post-hoc test was used to determine subgroups with respect to the results of one-way ANOVA ( $\mathrm{p}<0.05$ ).

\section{Results and Discussion}

In this study, effects of the various sports training programs applied to 5-9 year old children on some of their physical characteristics were investigated. 
Table 2. Descriptive Statistics of the Subjects

\begin{tabular}{|c|c|c|c|c|c|c|}
\hline & & $\mathrm{N}$ & Lowest & Highest & Average & Std. Dev. \\
\hline \multirow{3}{*}{ Body Weight (kg) } & 1. Measurement & 98 & 13,70 & 45,40 & 23,10 & 5,92 \\
\hline & 2. Measurement & 98 & 13,80 & 51,50 & 24,06 & 6,24 \\
\hline & 3. Measurement & 98 & 14,70 & 51,30 & 24,85 & 6,35 \\
\hline \multirow{3}{*}{ Length (cm) } & 1. Measurement & 98 & 99,00 & 151,00 & 117,50 & 10,14 \\
\hline & 2. Measurement & 98 & 98,60 & 142,00 & 119,02 & 9,40 \\
\hline & 3. Measurement & 98 & 102,00 & 143,00 & 120,91 & 9,14 \\
\hline \multirow{3}{*}{ BMI (kg / m²) } & 1. Measurement & 98 & 10,04 & 25,60 & 16,55 & 2,53 \\
\hline & 2. Measurement & 98 & 12,77 & 27,04 & 16,75 & 2,45 \\
\hline & 3. Measurement & 98 & 12,59 & 26,17 & 16,78 & 2,47 \\
\hline \multirow{3}{*}{ Vertical Jump (cm) } & 1. Measurement & 98 & 1,00 & 32,00 & 14,90 & 6,16 \\
\hline & 2. Measurement & 98 & 4,00 & 38,00 & 17,28 & 5,81 \\
\hline & 3. Measurement & 98 & 5,00 & 32,00 & 18,37 & 5,65 \\
\hline \multirow{3}{*}{ Throwing Medicine Ball } & 1. Measurement & 98 & 100,00 & 470,00 & 209,24 & 87,27 \\
\hline & 2. Measurement & 98 & 20,00 & 476,00 & 217,95 & 92,66 \\
\hline & 3. Measurement & 98 & 94,00 & 520,00 & 242,87 & 97,83 \\
\hline \multirow{3}{*}{ Balance Right } & 1. Measurement & 98 &, 50 & 19,70 & 5,44 & 3,81 \\
\hline & 2. Measurement & 98 & 1,00 & 15,29 & 5,65 & 3,42 \\
\hline & 3. Measurement & 98 & 0,00 & 25,00 & 6,79 & 4,25 \\
\hline \multirow{3}{*}{ Balance Left } & 1. Measurement & 98 & 67 & 28,20 & 5,21 & 4,50 \\
\hline & 2. Measurement & 98 & 0,00 & 25,40 & 5,08 & 3,45 \\
\hline & 3. Measurement & 98 & 0,00 & 25,40 & 6,32 & 4,28 \\
\hline \multirow{3}{*}{ Hand Grip Right } & 1. Measurement & 93 & 3,90 & 17,60 & 9,94 & 2,85 \\
\hline & 2. Measurement & 93 & 5,20 & 19,20 & 10,45 & 2,90 \\
\hline & 3. Measurement & 93 & 1,70 & 19,60 & 10,84 & 3,13 \\
\hline \multirow{3}{*}{ Hand Grip Left } & 1. Measurement & 93 & 5,20 & 16,70 & 9,64 & 2,73 \\
\hline & 2. Measurement & 93 & 5,00 & 17,90 & 9,94 & 2,80 \\
\hline & 3. Measurement & 93 & 5,90 & 19,10 & 10,74 & 3,13 \\
\hline \multirow{3}{*}{ Twisted Arm Hanging } & 1. Measurement & 98 & 0,00 & 36,11 & 3,89 & 6,23 \\
\hline & 2. Measurement & 98 & 0,00 & 53,97 & 5,41 & 8,09 \\
\hline & 3. Measurement & 96 & 0,00 & 32,00 & 4,50 & 5,44 \\
\hline \multirow{3}{*}{ Shuttle } & 1. Measurement & 95 & 0 & 28 & 9,82 & 7,00 \\
\hline & 2. Measurement & 95 & 0 & 28 & 12,47 & 6,95 \\
\hline & 3. Measurement & 95 & 0 & 25 & 12,95 & 6,05 \\
\hline \multirow{3}{*}{ Sit-and-reach } & 1. Measurement & 98 & 14,5 & 42,5 & 29,12 & 6,11 \\
\hline & 2. Measurement & 98 & 16,00 & 42,50 & 30,14 & 5,75 \\
\hline & 3. Measurement & 98 & 12,00 & 42,00 & 30,39 & 6,03 \\
\hline \multirow{3}{*}{ Horizontal Jump (cm) } & 1. Measurement & 98 & 10 & 157 & 90,69 & 24,33 \\
\hline & 2. Measurement & 98 & 38 & 163 & 100,91 & 21,89 \\
\hline & 3. Measurement & 98 & 48 & 165 & 103,43 & 21,46 \\
\hline \multirow{3}{*}{ 10x5 m Running (sec) } & 1. Measurement & 98 & 22,60 & 47,90 & 30,68 & 4,043 \\
\hline & 2. Measurement & 98 & 21,80 & 55,30 & 29,06 & 4,70 \\
\hline & 3. Measurement & 98 & 20,00 & 52,89 & 27,94 & 5,03 \\
\hline
\end{tabular}


Table 3. ANOVA Test Results

\begin{tabular}{|c|c|c|c|c|c|c|}
\hline & & Sum of Squares & Degree of Freedom & Squares Average & $\mathrm{F}$ & $p$-value \\
\hline \multirow{3}{*}{ Body Weight (kg) } & Between Groups & 59,981 & 2 & 29,991 & 825 & 439 \\
\hline & In-group & 10577,334 & 291 & 36,348 & & \\
\hline & Total & 10637,315 & 293 & & & \\
\hline \multirow{3}{*}{ Length (cm) } & Between Groups & 151,027 & 2 & 75,514 & ,771 & ,463 \\
\hline & In-group & 28499,979 & 291 & 97,938 & & \\
\hline & Total & 28651,006 & 293 & & & \\
\hline \multirow{3}{*}{$\mathrm{BMI}\left(\mathrm{kg} / \mathrm{m}^{2}\right)$} & Between Groups & 3,214 & 2 & 1,607 & ,261 & ,771 \\
\hline & In-group & 1792,293 & 291 & 6,159 & & \\
\hline & Total & 1795,507 & 293 & & & \\
\hline \multirow{3}{*}{ Vertical Jump (cm) } & Between Groups & 614,849 & 2 & 307,424 & 8,890 & ,000 \\
\hline & In-group & 10063,166 & 291 & 34,581 & & \\
\hline & Total & 10678,014 & 293 & & & \\
\hline \multirow{3}{*}{ Throwing Medicine Ball } & Between Groups & 59687,068 & 2 & 29843,534 & 3,474 & 032 \\
\hline & In-group & 2499922,143 & 291 & 8590,798 & & \\
\hline & Total & 2559609,211 & 293 & & & \\
\hline \multirow{3}{*}{ Balance Right } & Between Groups & 103,628 & 2 & 51,814 & 3,508 & 031 \\
\hline & In-group & 4298,660 & 291 & 14,772 & & \\
\hline & Total & 4402,289 & 293 & & & \\
\hline \multirow{3}{*}{ Balance Left } & Between Groups & 90,584 & 2 & 45,292 & 2,688 & 070 \\
\hline & In-group & 4903,230 & 291 & 16,850 & & \\
\hline & Total & 4993,814 & 293 & & & \\
\hline \multirow{3}{*}{ Hand Grip Right } & Between Groups & 37,343 & 2 & 18,671 & 2,127 & , 121 \\
\hline & In-group & 2422,888 & 276 & 8,779 & & \\
\hline & Total & 2460,231 & 278 & & & \\
\hline \multirow{3}{*}{ Hang Grip Left } & Between Groups & 60,074 & 2 & 30,037 & 3,596 & 029 \\
\hline & In-group & 2305,552 & 276 & 8,353 & & \\
\hline & Total & 2365,626 & 278 & & & \\
\hline \multirow{3}{*}{ Twisted Arm Hanging } & Between Groups & 115,115 & 2 & 57,558 & 1,286 & ,278 \\
\hline & In-group & 12933,748 & 289 & 44,753 & & \\
\hline & Total & 13048,863 & 291 & & & \\
\hline \multirow{3}{*}{ Shuttle } & Between Groups & 539,432 & 2 & 269,716 & 6,043 & ,003 \\
\hline & In-group & 12586,379 & 282 & 44,633 & & \\
\hline & Total & 13125,811 & 284 & & & \\
\hline \multirow{3}{*}{ Sit-and-reach } & Between Groups & 89,543 & 2 & 44,771 & 1,258 & 286 \\
\hline & In-group & 10352,526 & 291 & 35,576 & & \\
\hline & Total & 10442,068 & 293 & & & \\
\hline \multirow{3}{*}{ Horizontal Jump (cm) } & Between Groups & 8913,313 & 2 & 4456,656 & 8,729 & ,000 \\
\hline & In-group & 148565,990 & 291 & 510,536 & & \\
\hline & Total & 157479,303 & 293 & & & \\
\hline \multirow{3}{*}{ 10x5 m Running (sec) } & Between Groups & 491,223 & 2 & 245,611 & 11,233 & ,000 \\
\hline & In-group & 6362,888 & 291 & 21,866 & & \\
\hline & Total & 6854,111 & 293 & & & \\
\hline
\end{tabular}

\section{$\mathrm{P}<0.05$}

The average heights of children were measured as $117.5 \mathrm{~cm}$ in the first measurement, $119.02 \mathrm{~cm}$ in the second measurement and $120.91 \mathrm{~cm}$ in the last measurement. Their body weights were measured as $23.10 \mathrm{~kg}$ at the first measurement, $24.06 \mathrm{~kg}$ at the second measurement and $24.87 \mathrm{~kg}$ at the last measurement. These values are compatible with the literature. In a study, it was measured that boys with an average age of 6.8 had a height of $124 \pm 5$ and girls with an average age of 6.7 had a height of $122 \mathrm{~cm} \pm 5$. In the same study, body weight of the boys was measured as 24.5 $\mathrm{kg} \pm 3.7$ while body weight of the girls was measured as $23.8 \pm 3.4$ (Dencker, Hermansen, Bugge, Froberg, \& Andersen, 2011). Another study was conducted on 9-year-old children. In this study the average height of boys and girls were measured as $133.5 \mathrm{~cm}, 134.6 \mathrm{~cm}$, respectively and the average weight of boys and girls together was measured as 32.1 $\mathrm{kg}$ (Ramirez-Velez et al., 2017). In another study on children with a mean age of 7.4, the average height of boys and girls were measured as $126 \mathrm{~cm} \pm 6 \mathrm{~cm}$ and $125 \mathrm{~cm} \pm 5$, respectively and the average weight of boys and girls together was measured as $26 \mathrm{~kg}$ (Edwards et al., 2016).

Despite the small changes in measurements, the BMI values are not statistically significant. The mean BMI value was 
normal, and although some children participating in the study are overweight, but no subjects exceed the obesity limit. Measurements are similar to the literature. In a study conducted on a child group with a mean age of 4.91 , the BMI average of the children was measured as 16.42 (Cadenas-Sanchez et al., 2016). In another study, the BMI average values of 5-year-old children and 6-7 year-old children were measured as 14.08 and 15.07, respectively (Fry, Irwin, Nicoll, \& Ferebee, 2015). In an another study, the boys with an average age of 6.8 were found to have a BMI of $15.9 \pm$ 1.7 and the girls with a mean age of 6.7 were found to have a BMI of $16.0 \pm 1.6$ (Dencker et al., 2011). The BMI measurements of 9-year-old children were calculated to be 17.8 for males and 17.6 for females (Ramirez-Velez et al., 2017). In the study conducted on the children with a mean age of 7.4, the BMI value was calculated to be 17 for females and 16 for males (Edwards et al., 2016). In an another study, the boys with age of 9 were found to have a BMI of 16.7 \pm 1.7 (Bayraktar, Yaman, Zorba, Yaman \& Günay, 2016). The BMI measurements of 7-year-old children were calculated to be 15.96 for males and 15.57 for females (Deliceoğlu, Zorba, Yaman, Pekel \& Bayraktar, 2013).

A statistically significant difference was found between the first and second measurements for the vertical jump values of the subjects $(\mathrm{p}<0.05)$. Although there was a significant difference between the first and third measurements, no significant difference was found between the second and third measurements. In a study conducted on children aged 9 years, the vertical jump performances were measured, and an average jump height of $24.0 \mathrm{~cm}$ and $22.3 \mathrm{~cm}$ was obtained for the participating boys and girls, respectively (Ramirez-Velez et al., 2017).

Table 4. Vertical Jump TUKEY Test

\begin{tabular}{llll}
\hline \multirow{2}{*}{ Period } & N & Subset for alpha $=0.05$ & \\
\hline 1 & 98 & 1 & 17,28 \\
2 & 98 & 14,90 & 18,37 \\
3 & 98 & &, 397 \\
\hline Sig. & & 1,000 & 2 \\
\hline
\end{tabular}

The difference between the first and second measurements and between the second and third measurements in the medicine ball throwing test is statistically significant. A statistically significant difference was found between the first and second measurements and also between the second and third measurements in terms of right foot balance posture measurements $(p<0.05)$. A statistically significant difference was also found between the first and second measurements in the both left hand grip force and shuttle tests, but no statistically significant difference was determined between the second and third measurements.

Table 5. Medicine Ball Throwing TUKEY Test

\begin{tabular}{|c|c|c|c|}
\hline \multirow[b]{2}{*}{ Period } & \multicolumn{3}{|c|}{ Subset for alpha $=0.05$} \\
\hline & $\mathrm{N}$ & 1 & 2 \\
\hline 1 & 98 & 209,24 & \\
\hline 2 & 98 & 217,95 & 217,95 \\
\hline 3 & 98 & & 242,87 \\
\hline Sig. & & ,788 & , 146 \\
\hline
\end{tabular}

A statistically significant difference was found in right foot balance posture measurements of the participant children ( $\mathrm{p}$ $<0.05)$. The difference between the first and second measurements and between the second and third measurements is statistically significant for this characteristics $(\mathrm{p}<0.05)$. Although there was a development in left foot balance, no statistically significant difference was found in the relevant tests.

Table 6. Right Foot Balance TUKEY Test

\begin{tabular}{|c|c|c|c|}
\hline \multirow[b]{2}{*}{ Period } & \multirow[b]{2}{*}{$\mathrm{N}$} & \multicolumn{2}{|c|}{ Subset for alpha $=0.05$} \\
\hline & & 1 & 2 \\
\hline 1 & 98 & 5,443 & \\
\hline 2 & 98 & 5,653 & 5,653 \\
\hline 3 & 98 & & 6,794 \\
\hline Sig. & & ,923 &, 096 \\
\hline
\end{tabular}

The development of the left hand measurement values was observed in the grip force measurements. This development is also statistically significant ( $\mathrm{p}<0.05$ ). The development between both the first and second measurements and between the second and third measurements is statistically significant. Although there is a development in children's values of right hand grip force measurements, this development is not statistically significant ( $\mathrm{p}<0.05)$. In a study on Australian children, the children's hand grip force measurements were taken as follows; minimum 0 maximum $19.5 \mathrm{~kg}$ for $5 \mathrm{years}$ 
old, minimum 0 maximum $22 \mathrm{~kg}$ for 6 years old, minimum 0 maximum $26.5 \mathrm{~kg}$ for 7 years old, minimum 2 max $28 \mathrm{~kg}$ for 8 years old, and minimum 0 maximum $35 \mathrm{~kg}$ for 9 years old (Cochrane, Davey, \& de Castella, 2017).

Table 7. Left Hand Grip Force TUKEY Test

\begin{tabular}{llll}
\hline \multirow{2}{*}{ Period } & N & Subset for alpha $=0.05$ & \\
\hline 1 & 93 & 1 & 9,939 \\
\hline 2 & 93 & 9,637 & 10,737 \\
\hline 3 & 93 & 9,939 &, 146 \\
\hline Sig. & &, 756 & \\
\hline
\end{tabular}

The children were subjected to a twisted arm hanging test. Although the development was seen between the periods, this development was not statistically significant. Again the development of sit-and-reach flexibility test is not statistically significant.

The development in the shuttle test was also statistically significant ( $\mathrm{p}<0.05)$. The difference between the first and second measurements was significant, while the second and third measurements continued to improve, but the difference between the latters was found to be statistically insignificant.

Table 8. Shuttle Activity TUKEY Test

\begin{tabular}{llll}
\hline \multirow{2}{*}{ Period } & $\mathrm{N}$ & Subset for alpha $=0.05$ & \\
\hline 1 & 95 & 1 & 2 \\
\hline 2 & 95 & 9,82 & 12,47 \\
\hline 3 & 95 & & 12,95 \\
\hline Sig. & & 1,000 &, 877 \\
\hline
\end{tabular}

While there was a statistically significant difference between the first and second measurements in the horizontal jump test, the difference between the second and third measurements was not statistically significant. In the study conducted on a subject group with a mean age of 4.91, the long jump distance was measured as $78.23 \mathrm{~cm}$ (Cadenas-Sanchez et al., 2016). In another study, the long jump-stop measurements of 5-6 year old children were taken. The long jump-stop distance of boys and girls aged 5 years was measured as $83.61 \mathrm{~cm}( \pm 24.23)$ and $75.48 \mathrm{~cm}( \pm 21.38)$ respectively. This distance in 6 years old boys and girls was measured as $88.96 \mathrm{~cm}( \pm 21.75)$ and $84.27 \mathrm{~cm}( \pm 21.38)$, respectively (Latorre-Roman, Garcia-Pinillos, \& Mora-Lopez, 2017). In an another study, the longest and shortest jump-stop distances of 8-year-old children were measured as $18 \mathrm{~cm}$ and $181.5 \mathrm{~cm}$, while the same distances of 8-year-old children were measured as $42 \mathrm{~cm}$ and $193 \mathrm{~cm}$, respectively (Cochrane et al., 2017).

Table 9. Horizontal Jump TUKEY Test

\begin{tabular}{|c|c|c|c|}
\hline \multirow[b]{2}{*}{ Period } & \multirow[b]{2}{*}{$\mathrm{N}$} & \multicolumn{2}{|c|}{ Subset for alpha $=0.05$} \\
\hline & & 1 & 2 \\
\hline 1 & 98 & 90,69 & \\
\hline 2 & 98 & & 100,91 \\
\hline 3 & 98 & & 103,43 \\
\hline Sig. & & 1,000 &, 715 \\
\hline
\end{tabular}

$10 \times 5 \mathrm{~m}$ shuttle running practice was applied to the subjects. The development pattern obtained in these test results are also statistically significant. The differences between the first and second measurements and between the second and third measurements found to be significant as well $(\mathrm{p}<0.05)$.

Table 10. 10x5m Shuttle Run TUKEY Test

\begin{tabular}{llll}
\hline Period & N & Subset for alpha $=0.05$ & \\
\hline 3 & 98 & 1 & 27,939 \\
\hline 2 & 98 & 29,063 & 30,677 \\
\hline 1 & 98 & & 1,000 \\
\hline Sig. & &, 204 & \\
\hline
\end{tabular}

\section{Conclusions and Recommendations}

Many studies have investigated effects of physical activity on children. In general, the studies has concentrated on the effects of only one sport branch. However, the implementation of programs involving more than one sporting activity 
for children will ensure their development to be multifaceted. This situation contributes to both their physical development and general health status. It will also be a great advantage when they start with performance goals for a sports branch. Children who will be physically more inclined to performance will also have the chance to identify the branches they will like, by experiencing many branches.

\section{References}

Andersen, L. B., Harro, M., Sardinha, L. B., Froberg, K., Ekelund, U., Brage, S., \& Anderssen, S. A. (2006). Physical activity and clustered cardiovascular risk in children: a cross-sectional study (The European Youth Heart Study). Lancet, 368(9532), 299-304. https://doi.org/10.1016/S0140-6736(06)69075-2

Bayraktar, I., Yaman, N., Zorba, E., Yaman, M., \& Günay, M. (2016). The Analysis of Certain Differences in Motor Skills of Sedentary Male Children in the 9-14 Age Group Based on the Biological Maturity. Universal Journal of Educational Resarch, 4(8), 1894-1902. https://doi.org/10.13189/ujer.2016.040820

Cadenas-Sanchez, C., Martinez-Tellez, B., Sanchez-Delgado, G., Mora-Gonzalez, J., Castro-Pinero, J., Lof, M., ... Ortega, F. B. (2016). Assessing physical fitness in preschool children: Feasibility, reliability and practical recommendations for the PREFIT battery. Journal of Science and Medicine in Sport, 19(11), 910-915. https://doi.org/10.1016/j.jsams.2016.02.003

Chang, Y. K., Labban, J. D., Gapin, J. I., \& Etnier, J. L. (2012). The effects of acute exercise on cognitive performance: A meta-analytic review (vol 1453, pg 87, 2012). Brain Research, 1470, 159-159. https://doi.org/10.1016/j.brainres.2012.06.039

Chomitz, V. R., Slining, M. M., Mcgowan, R. J., Mitchell, S. E., Dawson, G. F., \& Hacker, K. A. (2009). Is There a Relationship Between Physical Fitness and Academic Achievement? Positive Results From Public School Children in the Northeastern United States. Journal of School Health, 79(1), 30-36. https://doi.org/10.1111/j.1746-1561.2008.00371.x

Cochrane, T., Davey, R. C., \& de Castella, F. R. (2017). Anthropometric standards for Australian primary school children: Towards a system for monitoring and supporting children's development. Journal of Science and Medicine in Sport, 20(3), 284-289. https://doi.org/10.1016/j.jsams.2016.08.015

Dencker, M., Hermansen, B., Bugge, A., Froberg, K., \& Andersen, L. B. (2011). Predictors of VO(2)Peak in Children Age 6-to 7-Years-Old. Pediatric Exercise Science, 23(1), 87-96. https://doi.org/10.1123/pes.23.1.87

Deliceoğlu, G., Zorba, E., Yaman, M., Pekel, H. A., \& Bayraktar I. (2013). The Investigation of Childrens Anthropometric and Motoric Attributes According To Their Ages. The Online Journal of Recreation and Sport, 2(2), 29-34.

Edwards, N. M., Kalkwarf, H. J., Woo, J. G., Khoury, P. R., Daniels, S. R., \& Urbina, E. M. (2016). Child Physical Activity Associations With Cardiovascular Risk Factors Differ by Race. Pediatric Exercise Science, 28(3), 397-406. https://doi.org/10.1123/pes.2015-0189

Engelen, L., Bundy, A. C., Naughton, G., Simpson, J. M., Bauman, A., Ragen, J., ... van der Ploeg, H. P. (2013). Increasing physical activity in young primary school children-it's child's play: A cluster randomised controlled trial. Preventive Medicine, 56(5), 319-325. https://doi.org/10.1016/j.ypmed.2013.02.007

Fry, A. C., Irwin, C. C., Nicoll, J. X., \& Ferebee, D. E. (2015). Muscular Strength and Power in 3-to 7-Year-Old Children. Pediatric Exercise Science, 27(3), 345-354. https://doi.org/10.1123/pes.2014-0152

Jager, K., Schmidt, M., Conzelmann, A., \& Roebers, C. M. (2014). Cognitive and physiological effects of an acute physical activity intervention in elementary school children. Frontiers in Psychology, 5, 1473. https://doi.org/10.3389/fpsyg.2014.01473

Latorre-Roman, P. A., Garcia-Pinillos, F., \& Mora-Lopez, D. (2017). Reference Values of Standing Long Jump in Preschool Children: A Population-Based Study. Pediatric Exercise Science, 29(1), 116-120.

Lobo, Y. B., \& Winsler, A. (2006). The effects of a creative dance and movement program on the social competence of head start preschoolers. Social Development, 15(3), 501-519. https://doi.org/10.1111/j.1467-9507.2006.00353.x

Martin-Garcia, M., Vila-Maldonado, S., Rodriguez-Gomez, I., Faya, F. M., Plaza-Carmona, M., Pastor-Vicedo, J. C., \& Ara, I. (2016). The Spanish version of the Three Factor Eating Questionnaire-R21 for children and adolescents (TFEQ-R21C): Psychometric analysis and relationships with body composition and fitness variables. Physiology \& Behavior, 165, 350-357. https://doi.org/10.1016/j.physbeh.2016.08.015 
Ortega, F. B., Silventoinen, K., Tynelius, P., \& Rasmussen, F. (2012). Muscular strength in male adolescents and premature death: cohort study of one million participants. British Medical Journal, 345. https://doi.org/10.1136/bmj.e7279

Padilla-Moledo, C., Ruiz, J. R., Ortega, F. B., Mora, J., \& Castro-Pinero, J. (2012). Associations of Muscular Fitness with Psychological Positive Health, Health Complaints, and Health Risk Behaviors in Spanish Children and Adolescents. Journal of Strength and Conditioning Research, 26(1), 167-173. https://doi.org/10.1519/JSC.0b013e31821c2433

Park, M. H., Falconer, C., Viner, R. M., \& Kinra, S. (2012). The impact of childhood obesity on morbidity and mortality in adulthood: a systematic review. Obesity Reviews, 13(11), 985-1000. https://doi.org/10.1111/j.1467-789X.2012.01015.x

Ramirez-Velez, R., Correa-Bautista, J. E., Lobelo, F., Cadore, E. L., Alonso-Martinez, A. M., \& Izquierdo, M. (2017). Vertical Jump and Leg Power Normative Data for Colombian Schoolchildren Aged 9-17.9 Years: The FUPRECOL Study. Journal of Strength and Conditioning Research, 31(4), 990-998. https://doi.org/10.1519/JSC.0000000000001550

Prevalence of insufficient physical activity. (2017). World Health Organization, from, http://www.who.int/gho/ncd/risk_factors/physical_activity_text/en/

Ruiz, J. R., Castro-Pinero, J., Artero, E. G., Ortega, F. B., Sjostrom, M., Suni, J., \& Castillo, M. J. (2009). Predictive validity of health-related fitness in youth: a systematic review. British Journal of Sports Medicine, 43(12), 909-923. https://doi.org/10.1136/bjsm.2008.056499

Sağıroğlu, İ., Kurt, C., Ömürlü, İ. K., \& Çatıkkaş, F. (2016). Does hand grip strength change with gender? The traditional method vs. the allometric normalisation method. European Journal of Physical Education and Sport Science, 2(6), 84-93.

Smith, J. J., Eather, N., Morgan, P. J., Plotnikoff, R. C., Faigenbaum, A. D., \& Lubans, D. R. (2014). The Health Benefits of Muscular Fitness for Children and Adolescents: A Systematic Review and Meta-Analysis. Sports Medicine, 44(9), 1209-1223. https://doi.org/10.1007/s40279-014-0196-4

Strong, W. B., Malina, R. M., Blimkie, C. J. R., Daniels, S. R., Dishman, R. K., Gutin, B., ... Trudeau, F. O. (2005). Evidence based physical activity for school-age youth. Journal of Pediatrics, 146(6), 732-737. https://doi.org/10.1016/j.jpeds.2005.01.055

Tan, S. J., Chen, C., Sui, M. Y., Xue, L. N., \& Wang, J. X. (2017). Exercise Training Improved Body Composition, Cardiovascular Function, and Physical Fitness of 5-Year-Old Children With Obesity or Normal Body Mass. Pediatric Exercise Science, 29(2), 245-253. https://doi.org/10.1123/pes.2016-0107

Weiss, R., \& Raz, I. (2006). Focus on childhood fitness, not just fatness. Lancet, 368(9532), $261-262$. https://doi.org/10.1016/S0140-6736(06)69051-X

\section{Copyrights}

Copyright for this article is retained by the author(s), with first publication rights granted to the journal.

This is an open-access article distributed under the terms and conditions of the Creative Commons Attribution license which permits unrestricted use, distribution, and reproduction in any medium, provided the original work is properly cited. 